\title{
Influence of Ground Heat Exchanger Zoning Operation on the GSHP System Long-Term Operation Performance
}

\author{
Mingzhi Yu \\ Kai Zhang
}

\author{
Hongmei Rang \\ Zhaohong Fang
}

Jinbao Zhao

\begin{abstract}
To alleviate the ground heat accumulation after long term running of ground source heat pumps (GSHP), ground heat exchanger (GHE) zoning operation can be adopted. Two GHE operation modes - zoning operation and full running - are compared in a case where heat release to the ground in summer is larger than the heat extraction from the ground in winter. In this study the soil thermal conductivity, volumetric specific heat capacity, borehole depth and spacing are $2.0 \mathrm{~W}(\mathrm{mK})^{-1}, 5.0 \times 10^{6} \mathrm{~J}\left(\mathrm{~m}^{3} \mathrm{~K}\right)^{-1}, 100 \mathrm{~m}$ and $5 \mathrm{~m}$ respectively with the boreholes arranged in a square $20 \times 20$ array. Under the given conditions the simulation results show that GHE zoning operation depresses the increase in amplitude of GHE outlet water temperature and so that the GSHP systems operate normally throughout the whole service life. By adopting GHE zoning operation, the energy consumption of the GSHP system is found to be reduced compared with that of a GHE operated without zoning. Operation without zoning shows that the GHE summer outlet water temperature increases faster than that with zoning operation and power demands are increased for the given GSHP load. Furthermore, in this case, the GSHP would not be able to run normally in the last several years due to the condensing temperature exceeding its upper limit.
\end{abstract}

\section{INTRODUCTION}

In the severe cold or the relatively warm regions, the summer and winter thermal loads imposed on the ground heat exchangers (GHE) of ground source heat pumps (GSHP) are usually unbalanced, i.e. the heat that the GHE rejects to the ground in summer is unequal to that absorbed from the ground in winter. For short term operation, unbalanced GHE thermal load will not induce excessive cold or heat accumulation in the ground as the ground heat dissipation capacity. However, for long term operation, summer and winter load imbalance would cause ground temperatures to successively increase or decrease (Cao, et.al, 2012) and the GSHP system operating efficiency would correspondingly decline. In extreme conditions the GHE may not be able to satisfy the thermal load on the GSHP system when the GHE outlet temperature approaches or exceeds the condensing temperature/pressure limit.

Nowadays, the main effective methods to alleviate the ground thermal accumulation include adopting hybrid 
ground coupled heat pump systems (HGCHP)(Xi, et.al, 2012; Wang, et.al, 2011; Liu, 2011; Man, et.al, 2011), enlarging the space between boreholes(Yu et.al, 2010; Kurevija et.al, 2012) and GSHP operating intermittently(Gao, et.al, 2006; Shang, et.al, 2012). The HGCHP systems are often used in cases with unbalanced thermal loads. For HGCHP systems, a cooling tower is typically adopted when the thermal load in summer is greater than that in winter and supplement heating equipment such as solar energy collector would be employed when the winter load is bigger than the summer load. Sometimes, for bigger winter load cases, some measures are used to inject heat into the ground in the other seasons so that the stored heat can be used in winter. Although the thermal accumulation can be inhibited effectively by the hybrid heat pump heating systems, the energy efficiency of supplementary loop or equipment is usually lower than that of GSHPs. Moreover, the operation and adjustment of a hybrid system is much more complex than that of a pure GSHP. In fact, enlarging the space between boreholes increases the ground volume occupied by the GHE and the ground temperature variation will maintain relatively even due to the increase of the total heat capacity of the GHE field. Enlarging borehole-spacing is a simple and practicable method, but it need more ground surface and is restricted in the places where is short of land. Intermittent operation provides time for the ground thermal recovery, but the power consumption of the compressor is increased. Moreover, the operation mode of a HVAC system is usually set according to the building demand, and hardly guarantee the operation time needed for ground thermal recovery.

This paper intends to use the GHE zoning operation method (Yu, et.al, 2016) to solve the problem of ground thermal accumulation.

\section{ZONING OPERATION STRATEGY}

During the long-term operation of the GSHP systems, the heat/cold accumulated in the central GHE field induced by the unbalanced seasonal thermal load hardly transfers to the field outside the GHE area even after many years. For the case with heat injection in summer is greater than heat extraction in winter, it is obvious that the thermal anomalies would be gradually aggravated with time extension if all buried pipes of the GHEs are utilized in winter and summer. Therefore with running time growth, the heat in the central GHE part would continue to accumulate and the soil temperature gradually increase, the heat exchange capacity of buried pipes in summer gradually decrease, and even cause the heat exchange of some buried pipe failures. For this case the zoning operation mode can be used, in which the whole GHE operates in summer and only the relatively central part of the GHE works in winter. For the systems only extract heat from the relatively central GHE area, the workload imbalance of the relatively central part of the GHE between summer and winter will drop significantly. Although this mode would make the soil temperature in the central region obviously lower than that with no zoning operation, which is not conducive to draw heat from the soil in winter but is helpful to release heat into the ground in summer. The zoning operation method can help eliminate underground heat accumulation and consequently, it is possible to improve the annual energy efficiency of the heat pump units and the long-term operational efficiency of the system. Furthermore, water pump power demands will be reduced as overall flow rates are lower during zoning operation.

\section{ANALYSIS AND DISCUSSION}

\section{Mathematic Model of Heat Transfer between GHE and Ground}

Assuming that the ground is a semi infinite media with uniform initial temperature and constant thermal properties, and the GHE is regarded as a group of finite line heat source, hence the finite line heat source model can be used to describe the heat transfer between the GHE and the ground. The soil temperature around a borehole can be obtained by the following equation (Zeng, et.al, 2002; Louis, et.al, 2007), 


$$
T=T_{0}+\frac{q}{4 \pi \lambda} \int_{0}^{H}\left[\frac{\operatorname{erfc}\left(\sqrt{r^{2}+(z-h)^{2}} / 2 \sqrt{a t}\right)}{\sqrt{r^{2}+(z-h)^{2}}}-\frac{\operatorname{erfc}\left(\sqrt{r^{2}+(z+h)^{2}} / 2 \sqrt{a t}\right)}{\sqrt{r^{2}+(z+h)^{2}}}\right] d h
$$

Where, $q_{l}$ is the heat release of a borehole per unit depth, $\mathrm{W} / \mathrm{m} ; \lambda_{S}$ is the ground thermal conductivity, $\mathrm{W} / \mathrm{m} \bullet \mathrm{K}$; $a$ is the ground thermal diffusivity, $\mathrm{m}^{2} / \mathrm{s} ; r$ is the distance from the center of the buried pipe, $\mathrm{m} ; z$ is the axial coordinate of the pipe, $\mathrm{m}$; and $H$ is the borehole depth, $\mathrm{m}$.

The temperature change of any point in the GHE area is the superposition of temperature rises induced by each borehole according to the superposition principle. For cases with inconstant load, the excess temperature can be obtained by considering the varying load as the integration of a series of step loads (Fang, et.al, 2002),

$$
\theta(x, y, z)=\sum_{i=1}^{n} \sum_{j=1}^{m} \frac{q_{i, j}-q_{i, j-1}}{4 \pi \lambda} \int_{0}^{H}\left[\frac{\operatorname{erfc}\left(\frac{\sqrt{r_{i}^{2}+(z-h)^{2}}}{2 \sqrt{a\left(t_{m}-t_{j-1}\right)}}\right)}{\sqrt{r_{i}^{2}+(z-h)^{2}}}-\frac{\operatorname{erfc}\left(\frac{\sqrt{r_{i}^{2}+(z+h)^{2}}}{2 \sqrt{a\left(t_{m}-t_{j-1}\right)}}\right)}{\sqrt{r_{i}^{2}+(z+h)^{2}}}\right] d h
$$

Where, $t$ is time, $s$, and

$$
r_{i}=\sqrt{\left(x-x_{i}\right)^{2}+\left(y-y_{i}\right)^{2}}
$$

Here, $\left(x_{i}, y_{i}\right)$ is the coordinate of the ith borehole.

\section{Model of the Heat Pump Unit}

A chiller model in the simulation program DOE-2 is used to analyse the heat pump unit (Hydemam, et.al, 2002). To simplify calculation, the cirlulating water flow rate is assumed constant. The power of the heat pump unit can be calculated by Equation 4 .

$$
P=C_{1} C_{2} P_{r}
$$

Where, $P_{r}$ is the input power that the heat pump unit needed at the rated state, $\mathrm{KW} ; C_{1}$, the input power correction coefficient; $C_{2}$ the input power correction coefficient of the heat pump unit at part load.

$$
\begin{gathered}
C_{1}=\alpha_{1}+\alpha_{2} T_{e o}+\alpha_{3} T_{e o}^{2}+\alpha_{4} T_{c i}+\alpha_{5} T_{c i}^{2}+\alpha_{6} T_{e o} T_{c i} \\
C_{2}=\beta_{1}+\beta_{2} P L R+\beta_{3} P L R^{2}
\end{gathered}
$$

Here, $a$ and $\beta$ are regression coefficients; PLR, the part load rate of the heat pump unit; $T_{e o}$ the outlet temperature of the evaporator, ${ }^{\circ} \mathrm{C}$; and $T_{i i}$ the inlet temperature of the condenser, ${ }^{\circ} \mathrm{C}$.

Table 1. Main Rated Parameters of the Heat Pump of EXLSR530.1

\begin{tabular}{cccccc}
\hline $\begin{array}{c}\text { Cooling } \\
\text { Capacity } \\
/ \mathrm{kJ} / \mathrm{h}\end{array}$ & COP & $\begin{array}{c}\text { Flow Rate at the } \\
\text { Chilled Water Side } \\
\text { of the Evaporator } \\
/ \mathbf{k g} / \mathrm{h}\end{array}$ & $\begin{array}{c}\text { FlowrRate at the Chilled } \\
\text { Water Side of the } \\
\text { Condenser/ kg/h }\end{array}$ & $\begin{array}{c}\text { Outlet Water } \\
\text { Temperature of the } \\
\text { Evaporator/ } /{ }^{\circ} \mathrm{C}\end{array}$ & $\begin{array}{c}\text { Return Water } \\
\text { Temperature of } \\
\text { the Condenser } /{ }^{\circ} \mathrm{C}\end{array}$ \\
\hline \hline 1576800 & 5 & 75265 & 88738 & 7 & 26.67 \\
\hline
\end{tabular}

The heat pump unit parameters used are according to the heat pump unit of EXLSR530.1 (A product of Neimenggu Yike Air Conditioning Equipment Limited Company). The main rated parameters are listed in Table 1. 
Coefficients of Equation 5 and 6 are obtained by nonlinear regression and then Eqations (5) and (6) can be rewritten as,

$$
\begin{aligned}
& C_{1}=0.7360+0.0189 T_{e o}-0.0015 T_{e o}^{2}+0.2167 T_{c i}+0.2055 T_{c i}^{2} \\
& C_{2}=0.2726-0.08413 P L R+0.8102 P L R^{2}
\end{aligned}
$$

\section{Model of the Pump}

The effective power of the pump is,

$$
N_{\mathrm{e}}=\gamma Q H / 1000
$$

Where, $N e$ is the energy water gained by the pump, KW; $\gamma$, the water volume weight, $\mathrm{N} / \mathrm{m}^{3}$; $Q$, water flow rater, $\mathrm{m}^{3} / \mathrm{s}$ and $H$ the pump delivery head, $\mathrm{m}$.

The shaft power of the pump is

$$
N=\frac{N_{\mathrm{e}}}{\eta}=\frac{\gamma Q H}{1000 \eta}
$$

Here, $\eta$ is the total efficiency of the pump, which is the product of volumetric efficiency, hydraulic efficiency and mechanic efficiency.

\section{Case Study}

A $20 \times 20$ matrix arrangement multi-borehole ground source heat pump system is adopted to analyze the zoning operation conditions which heating load in summer is significantly greater than the cooling load in winter. To cut down the calculation workload and simplify analysis, the GSHP system is assumed keeping on running and maintains constant all the time during summers and winters. The GHE heat injection in summer is $666 \mathrm{KW}$ and heat extraction in winter is $411 \mathrm{KW}$, the summer/winter load ratio is 1.6:1. All buried pipes of the GHE are utilized in summer and the outermost two rows of pipes stop running in winter, as shown in Figure 1. The reason to stop the outermost two rows of pipes running in winter is that, for running boreholes, the heat injection in summer approximately equals to the heat extraction in winter, which means loads maintain balanced in summer and winter. As a result, the thermal accumulation in the ground will be less serious than that of all boreholes running in both summer and winter. The main parameters of the boreholes and the ground are presented in Table 2. A buried pipe is assumed

\begin{tabular}{|c|c|c|c|c|}
\hline $\begin{array}{c}\text { Borehole Spacing } \\
\text { /m }\end{array}$ & $\begin{array}{c}\text { Borehole Depth } \\
\text { /m }\end{array}$ & $\begin{array}{c}\text { Soil Volume Specific } \\
\text { Heat Capacity } \\
/ \mathrm{J} \bullet\left(\mathrm{m}^{3} \bullet \mathrm{K}\right)^{-1} \\
\end{array}$ & $\begin{array}{l}\text { Soil Thermal } \\
\text { Conductivity } \\
/ \mathrm{W} \cdot(\mathrm{m} \cdot \mathrm{K})^{-1}\end{array}$ & $\begin{array}{l}\text { Soil Initial Temperature } \\
\qquad /{ }^{\circ} \mathrm{C}\end{array}$ \\
\hline 5 & 100 & $5.0 \times 10^{6}$ & 2.0 & 15 \\
\hline
\end{tabular}
failure when its outlet water temperature reaches $40^{\circ} \mathrm{C}$. The load that formerly undertook by the failure pipes are then shared by other pipes which outlet water temperature less than $40^{\circ} \mathrm{C}$.

Table 2. Main Parameters of Borehole and Soil Thermal Properties 

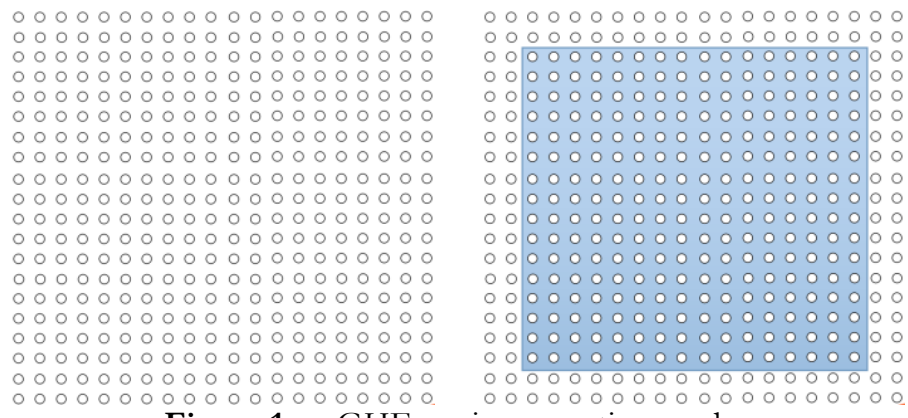

Figure 1 GHE zoning operation mode

Figure 2 is the monthly average outlet temperature of the GHE in the air-conditioning season which is running normally. The running time are 3 months in summer and winter respectively every year and the GSHP system stop running in the other 6 months, so the total running time in summer or winter are both 60 months when the ground source heat pump system was operating normally 20 years.
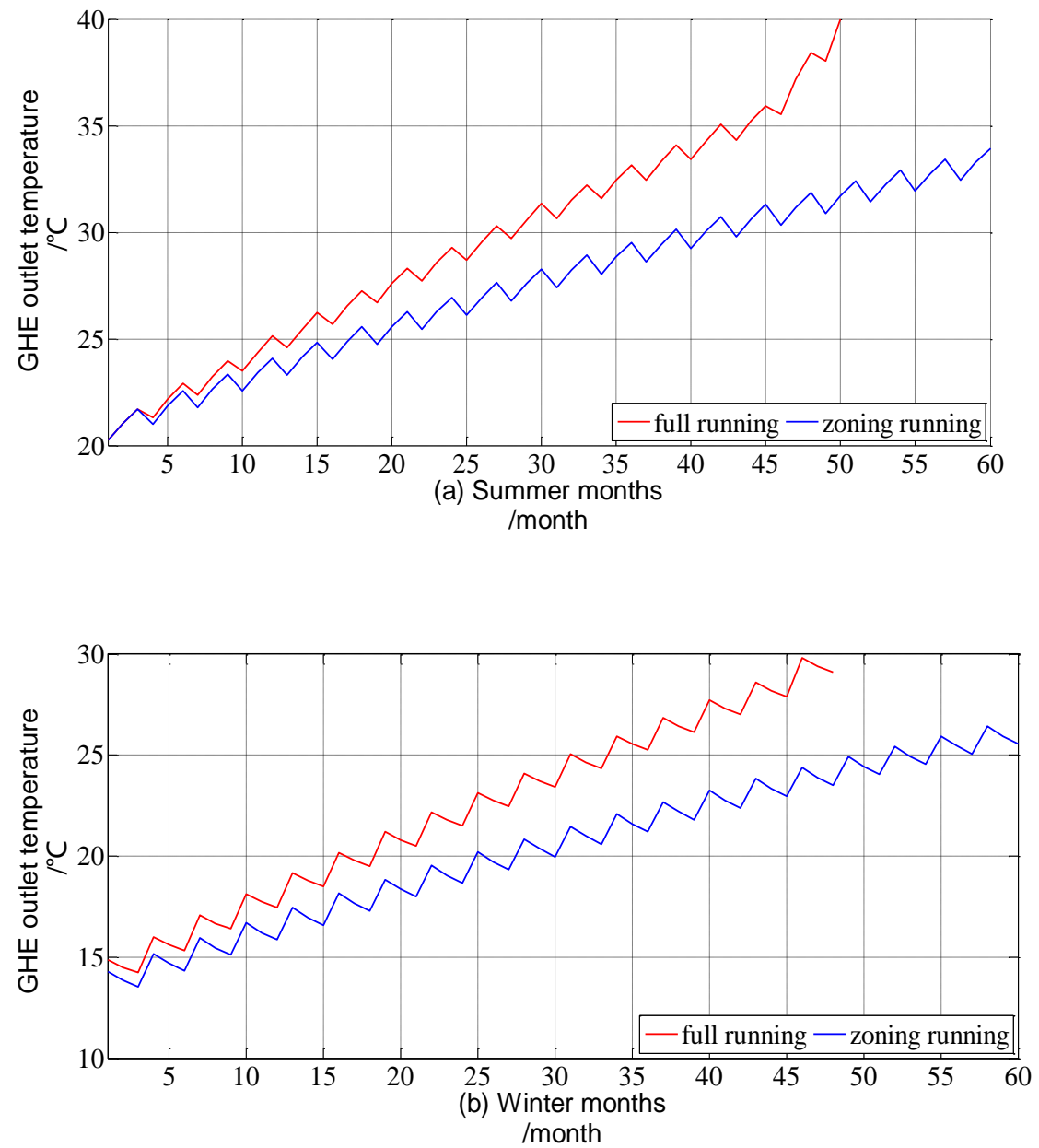

Figure 2 GHE outlet temperature vs. time 
For the two kinds of running modes have the same initial conditions in the first summer, so the summer average GHE outlet water temperature is $20.27^{\circ} \mathrm{C}$, and the water temperature rises to $21.70{ }^{\circ} \mathrm{C}$ at the end of this summer for both running modes. At the beginning of the next summer, the outlet water temperature of the two modes are all decreased due to the heat extraction in winter and thermal recovery in spring. From the second year, the outlet water temperature at zoning running mode is always lower than that at the full running mode, which enables the GSHP system running in a relative high efficiency way. With running time increase, the outlet water temperature of the zoning running becomes higher and higher because heat continues to be accumulated in the relative central area. As mentioned above, a buried pipe is considered failure when its outlet water temperature reaches $40^{\circ} \mathrm{C}$. After 15 years, i.e. 45 summer months, some buried pipes at the full running mode become failure for their outlet temperature exceed $40^{\circ} \mathrm{C}$ and cannot release heat normally in summer, therefore the outlet water temperature increases more rapidly for other pipes should bear more loads from the 15th year. The outlet water temperature of the whole buried pipe in the case of full running mode are all over $40^{\circ} \mathrm{C}$ in the 17 th year, which leads to the GSHP system cannot running normally anymore. At the same time, the outlet water temperature of every month in air-conditioning season is $30.89^{\circ} \mathrm{C}, 31.71{ }^{\circ} \mathrm{C}$ and $32.39^{\circ} \mathrm{C}$ respectively in the zoning operation case, which is far below than that at the full running mode. The above results show that the zoning operation mode can effectively reduce the thermal accumulation in the GHE field, which will guarantee the GSHP system runs normally in 20 years and even longer.

The GHE outlet water temperature in winter decreases month by month with both operation modes. The outlet water temperature at zoning running mode maintains lower than that at the full running mode from the first winter, and the temperature difference increases with operation time increases. Although the zoning operation reduces the outlet water temperature in winter which result in lower winter operation efficiency, the global annual efficiency is likely higher than that of full running operation due to bigger GHE outlet temperature in summer. As shown in Figure 2, the GSHP system operates normally in 20 years at zoning operation mode, while it can only work 15 years at full running mode.

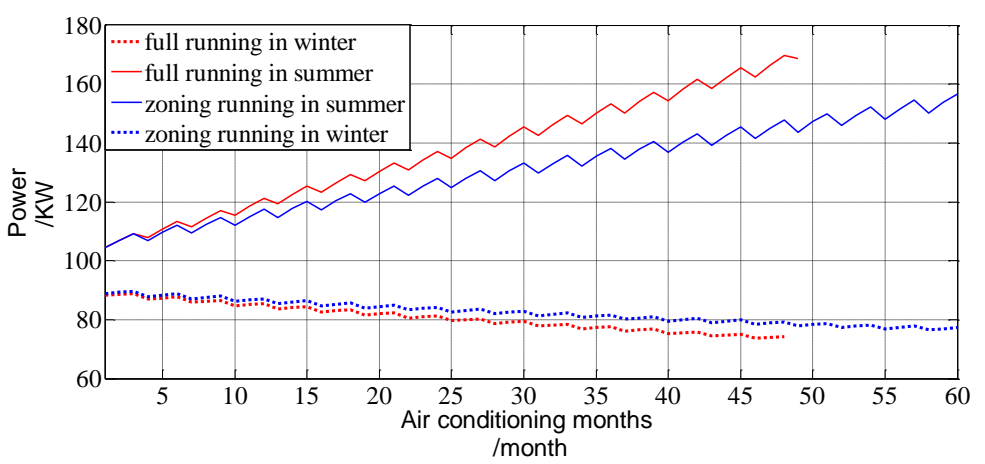

Figure 3 GSHP power vs. time

Figure 3 is the heat pump unit power needed in summers and winters. During the summer operation in the first year, the two operation modes have the same GHE outlet temperature and the heat pump unit requires same power $(104.5 \mathrm{~kW})$. At zoning operation mode which only put the inner $18 \times 18$ of buried pipes into use in winter, the GHE outlet temperature is lower than that at full running mode, and in the first winter the power needed of zoning running is $88.8 \mathrm{~kW}$ which is higher than that at full operation mode. From the second year, the two running modes are affected by thermal accumulation in the last summer and the outlet temperature and power needed are all increased. The power increase amplitude at zoning operation mode is lower than that at the full operation mode, therefore 
zoning running saves energy. Meanwhile, in winter, GHE outlet temperature at both modes increase and power needed decrease due to ground thermal accumulation. Power needed at zoning operation mode reduces less, which results in higher power needed comparing with that at full running mode. However, Figure 3 shows that, at full running mode, the power cut down in summers is much more than the power more consumed in winters. Therefore, comprehensively, the zoning running mode is more energy-saving comparing with the full running mode

\section{CONCLUSION}

This paper has analyzed the GHE outlet temperature and the heat pump unit power needed at zoning operation mode and full running mode by the case of the building load in summer is greater than that in winter, the results show that:

Zoning operation can significantly depress the GHE outlet water temperature increase due to ground thermal accumulation caused by unbalanced thermal load in winter and summer. This apparently improves the GSHP system operation efficiency.

Although power needed at zoning operation mode is higher than that at the full running mode in winter, it is far lower than that at full running mode in summer. Comprehensively, comparing with the full running mode, the zoning operation mode is energy-saving.

\section{ACKNOWLEDGMENTS}

This work is supported by the Natural Science Foundation of China (NSFC) No.51176104 and the State's Key Project of Research and Development Plan No. 2016YFC0700803-01.

\section{NOMENCLATURE}

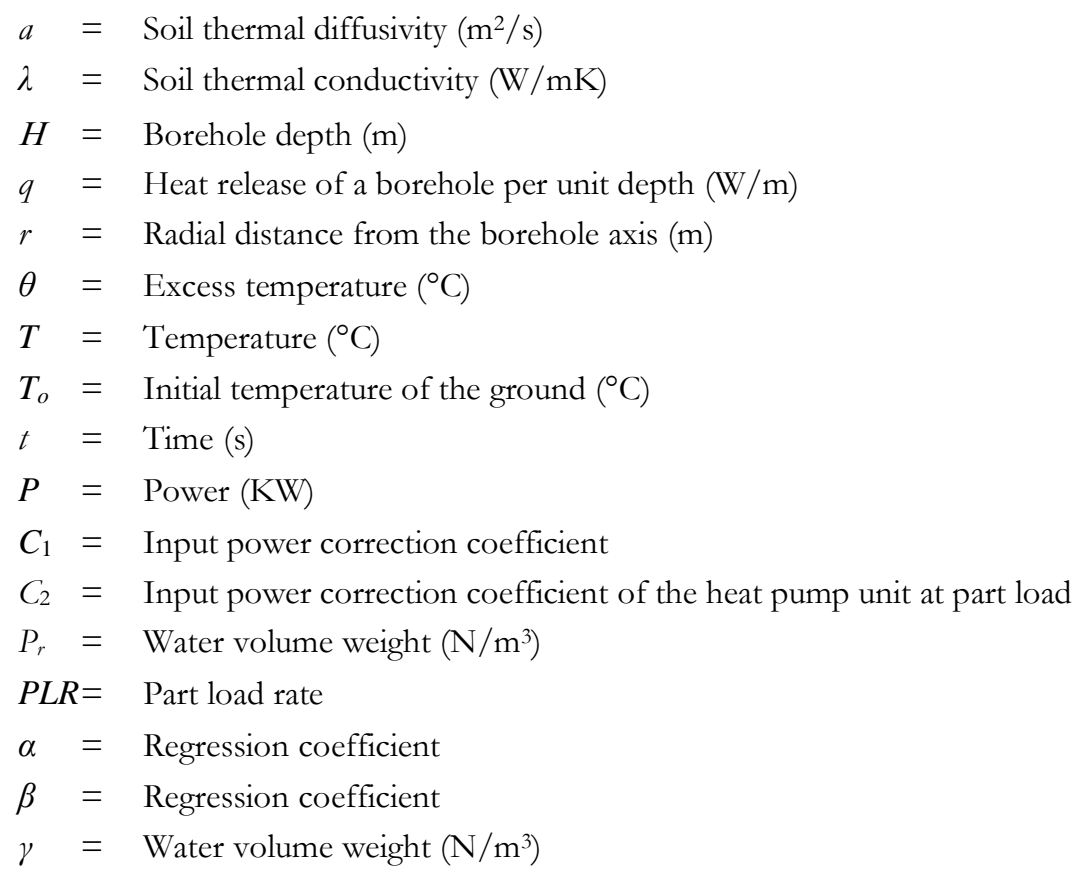

\section{Subscripts}

eo $=$ outlet of the evaporator

$c i=$ inlet of the condenser 


\section{REFERENCES}

Cao X., Y. Zhou and H. Fang. 2012. The Influence of Load Imbalance Rate on the Soil Temperature of the Ground Source Heat Pump System. Building Heat Energy Ventilation air Conditioning. 31 (5): 5-7.

Fang Z., N. Diao and P. Cui. 2002. Discontinuous operation of geothermal heat exchangers. Tsinghua Science \& Technology. 7(2):194-197

Gao Q., M. Li. and Y. Yan. 2006. Underground Wells Heat Transfer Enhancement and Operation Mode Influence. Acta Energiae Solaris Sinica. 27(1):83-89.

Hydemam M. and Gillespie K. 2002. Tools and Techniques to Calibrate Electric Chiller Component Models. ASHRAE Transactions. 108(1): 733-741.

Kurevija T., D. Vulin and V. Krapec. 2012. Effect of Borehole Array Geometry and Thermal Interferences on Geothermal Heat Pump System. Energy Conversion \& Management 60:134-142.

Liu Y. 2011. Coupling Characteristics of the Compound Heat Pump Heating System. Doctoral Dissertation. Harbin Institute of Technology. Harbin.

Louis L. and Benoit. 2007. A New Contribution to the Finite Line-Source Model for Geothermal Boreholes. Energy and Buildings 39(17): 188-198.

Maestre I. R., G. F. J. Gonzalez, P. A. Gomez, et al. 2013. Performance Assessment of a Simplified Hybrid Model for a Vertical Ground Heat Exchanger. Energy and Buildings 66: 437-444.

Man Y., H. Yang, J. D. Spitler, et al. 2011. Feasibility Study on Novel Hybrid Ground Coupled Heat Pump System with Nocturnal Cooling Radiator for Cooling Load Dominated Buildings. Applied Energy 88(11):4160-4171.

Shang Y., S. LI and L. Dai. 2012. Study of Characteristics of Soil Temperature Variation and Recovery under Intermittent Operation of Ground-Source Heat Pump. Journal of Dalian University of Technology 52(3): 350-356.

Wang C., B. Chen, M. Chen, et al. 2011. Solar-Earth Source Heat Pump System and Buried Pipe System. Acta Energiae Solaris Sinica 32(1): 77-82.

Xi. C. and H. Yang. 2012. Performance Analysis of a Proposed Solar Assisted Ground Coupled Heat Pump System. Applied Energy 97(9): 888-896.

Yu. B., F. Wang, L. Yan. 2010. Borehole Spacing and Layout Effect on Heat Transfer of Underground Pipe Group. Refrigeration \& Air Conditioning 10(5): 31-34.

Yu M, K. Zhang, X. Cao, et al. 2015. Zoning Operation of Multiple Borehole Ground Heat Exchangers to Alleviate the Ground Thermal Accumulation Caused by Unbalanced Seasonal Loads. Energy \& Buildings, 110: 345-352.

Zeng H., N. Diao, Z. Fang. 2002. A Finite Line-Source Model for Boreholes in Geothermal Heat Exchangers. Heat Transfer Asian Research 31(7): 558-567. 